\title{
A EDUCAÇÃO, O ENSINO DE HISTÓRIA E O CURRÍCULO MÍNIMO DO ESTADO DO RIO DE JANEIRO: CURRÍCULO ESCRITO, EM AÇÃO E FORMAÇÃO DE PROFESSORES
}

\author{
EDUCATION, THE TEACHING OF HISTORY AND THE MINIMUM CURRICULUM OF \\ THE RIO DE JANEIRO: RESUME WRITING, IN ACTION AND TRAINING OF \\ TEACHERS
}

Thiago Rodrigues Nascimento ${ }^{1}$

\begin{abstract}
RESUMO: A educação fluminense enfrenta, atualmente, uma crise. Os professores, a partir de mecanismos coercitivos propostos pela Secretaria de Estado de Educação (SEEDUC), têm a sua autonomia pedagógica ameaçada. A partir de fevereiro de 2011 começou a ser publicado o currículo mínimo das disciplinas que compõem os ensinos fundamental e médio. O objetivo deste artigo é analisar a construção do currículo mínimo, seus objetivos, o contexto em que foi elaborado e como os professores estão sendo formados (ou não) para trabalhar com esse documento. Discutimos sobre o lugar da História no currículo da rede estadual e o currículo mínimo de História. Tomamos como fonte, além dos documentos normativos elaborados pela SEEDUC, indicadores de avaliações como o Índice de Desenvolvimento da Educação Básica e notícias sobre a educação fluminense publicadas em periódicos.
\end{abstract}

Palavras-chave: Ensino de História. Currículo Mínimo. Formação de Professores.

ABSTRACT: The education of the Rio de Janeiro faces currently a crisis. The teachers, from coercive mechanisms proposed by the Secretary of State for Education (SEEDUC), have their pedagogic autonomy threatened. From February 2011 began publication the minimum curriculum of disciplines that make up the primary and secondary education. The purpose of this article is to analyze the construction of minimum curriculum, its objectives, the context in which it was drafted and how teachers are being trained (or not) to work with this document. We discussed about the place of history in the curriculum of the State network and the minimum curriculum History. We used as a source, in addition to the normative documents drawn up by SEEDUC, indicators of evaluations as the basic education development index and news about education of the Rio de Janeiro published in periodicals.

Keywords: History teaching. Minimum Curriculum. Teacher training.

1 Secretaria de Estado de Educação do Rio de Janeiro (SEEDUC/RJ). Mestre em História Social Universidade do Estado do Rio de Janeiro. 


\section{Introdução}

As recentes manifestações, realizadas no mês de junho em diferentes partes do Brasil, demonstraram o descontentamento da população com as administrações federal, estaduais e municipais. Os gastos desmedidos com a estrutura de poder e com eventos, como a Copa das Confederações, as Olimpíadas e a Jornada Mundial da Juventude, serviram como catalisadores dos protestos. Nesse sentido, no Estado do Rio de Janeiro milhares de pessoas foram às ruas exigir mudanças. Algumas estimativas apontam na faixa das 300 mil e outras em até 1 milhão de pessoas que decidiram reagir a falta de investimentos em saúde, segurança, transportes e educação. Não é errôneo dizer que o Estado passa por uma grande crise no início dessa segunda década do século XXI. O Governo de Sérgio Cabral (PMDB), iniciado em 2007, e em seu segundo mandato, enfrenta uma série de problemas.

Tratar da totalidade da crise levaria a necessidade de construção de uma pesquisa específica e fugiria aos objetivos que propomos para esse artigo. É necessário um trabalho de fôlego que demarque os principais aspectos da crise pela qual passa o Rio de Janeiro, os seus fatores e, talvez, possíveis soluções. Tomamos como objeto principal de discussão a educação pública estadual fluminense. A escolha não é aleatória. O pesquisador atua desde agosto de 2012 como professor de História da rede estadual de ensino, em turmas de $6^{\circ}, 8^{\circ}$ e $9^{\circ}$ anos do ensino fundamental. De fato, a SEEDUC é a maior empregadora dos recém egressos dos cursos de licenciatura. Atualmente, possui 74 mil professores, 1 milhão de alunos e 1.310 unidades escolares (Figura 1). Cerca de meio milhão dos discentes concentram-se na região metropolitana. Entretanto, apesar dos significativos números faltam escolas e professores para atender a crescente demanda dos alunos. Da mesma forma, muitas das escolas estão em situação precária e as condições salariais e de trabalho não são as melhores possíveis. Há uma contínua ausência de investimentos em infraestrutura, capacitação e valorização profissional.

Dados divulgados pelo Sindicato Estadual dos Profissionais de Educação (SEPE) do Rio de Janeiro, obtidos a partir de pesquisa no Diário Oficial, apontam que diariamente de 3 a 4 professores deixam a SEEDUC por pedido de 
exoneração, sem contar aposentadorias, mortes e demissão. De acordo com o Sindicato, até o início de maio de 2013, 306 concursados pediram exoneração. Isso leva a um quadro de constante carência de professores, principalmente em disciplinas como Matemática, Química, Física, Sociologia e Filosofia (SEPE, maio/2013).

Figura 1: Escolas por regional. Quantitativo de unidades escolares e alunos

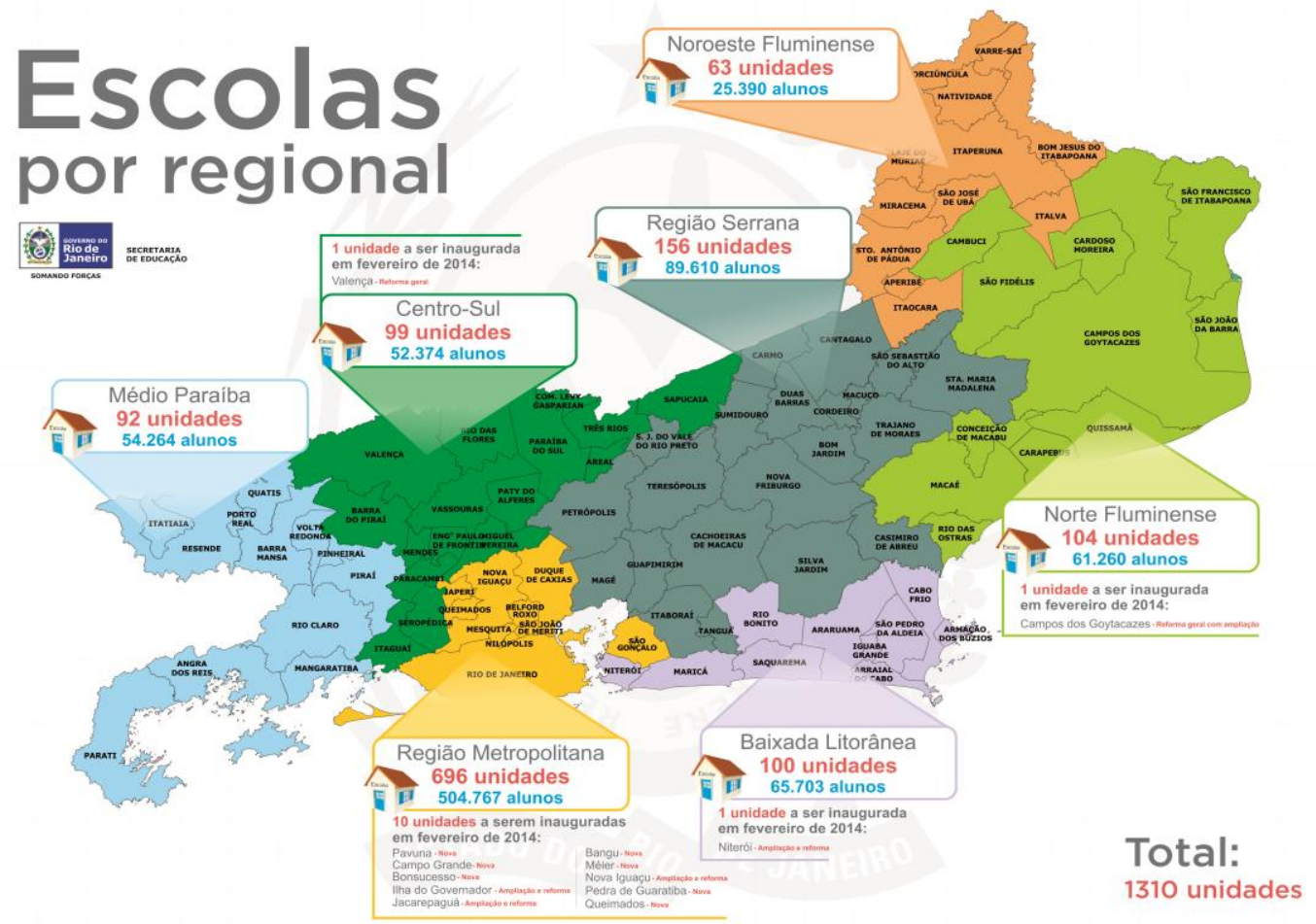

Fonte: Disponível em: <http://www.rj.gov.br/web/seeduc/exibeconteudo?articleid=1706456 $>$. Acesso em: 08 ago. 2013.

Os baixos salários, a forte pressão a que é submetido o professor (pelos alunos - falta de respeito; avaliações internas e externas impostas pela Secretaria; e na precariedade das escolas, com falta de materiais básicos de trabalho - como piloto, apagador e livro didático) são, para o SEPE, algumas das causas principais dos pedidos de exoneração. Para Maria José Quirino et alii (2011), "atualmente, no Estado do Rio de Janeiro, a autonomia pedagógica em sala de aula enfrenta obstáculos impostos 'de cima para baixo' devido às políticas de reformulação na educação". Dentre os aspectos das reformulações desenvolvidas a partir de 2011, quando Wilson Risolia assumiu o comando da 
Secretaria Estadual de Educação, destacam-se a implantação do currículo mínimo e da chamada bonificação por resultados. Através desse programa a Secretaria estabelece uma série de metas, como diminuição da reprovação de alunos, diminuição da evasão escolar, cumprimento integral do currículo mínimo, dentre outros. As escolas e professores que atingem as metas recebem um bônus. Trata-se de uma política desagregadora e que desqualifica o profissional de educação do Rio de Janeiro, colocando-o em constante atrito com os seus colegas de trabalho. A bonificação é para poucos.

Em julho de 2013, a Secretaria divulgou os resultados obtidos pelas escolas no ano anterior. Das 1.310 unidades escolares apenas 387 atingiram as metas estipuladas pelo Governo. Esse quantitativo representou $30 \%$ da rede. Entretanto, escolas que atingiram as metas, como por exemplo, C. E. José Bonifácio e C. E. Roberto Silveira, ambas situadas em Bom Jesus do Itabapoana, Noroeste Fluminense foram fechadas. Como explicar tal situação? Se a escola é boa, o que levou a sua extinção? Essa política vem sendo alvo da oposição dos professores. Em solidariedade aos docentes da rede estadual, professores da Faculdade de Educação da Universidade Federal do Rio de Janeiro lançaram um abaixo-assinado, no site Petição Pública, solicitando a saída do Secretário Wilson Risolia. Na Carta Aberta, assinalam o autoritarismo das políticas educacionais desenvolvidas de "cima para baixo" e demonstram contrariedade quanto ao lançamento da política de Certificação, programa que pretende avaliar o professorado através de provas anuais e com o objetivo de propor uma diferenciação salarial de acordo com o desempenho docente ${ }^{2}$.

Como professor e pesquisador, somos convidados a refletir sobre a atual situação do magistério e da educação fluminense. A reflexão é diária. Diária porque necessária. É uma reconstrução da prática e da expectativa. Expectativa quanto ao nosso trabalho, quanto ao futuro do aluno e, num plano bem maior, do estado ou do país. Que tipo de alunos o estado quer que formemos? Para que serve o ensino da História? (algo que todo aluno da escola básica pergunta ao seu professor). Como devem ser as atividades de ensino num momento em que os alunos não sabem ler ou escrever (no sentido da compreensão daquilo que

\footnotetext{
${ }^{2}$ A íntegra da Carta Aberta escrita por professores e professoras da Faculdade de Educação da Universidade Federal do Rio de Janeiro encontra-se disponível em Sepe (jul.2013).
} 
está fazendo, ler ou escrever é mais do que juntar palavras)? Diante destes questionamentos, abrangentes e variados, iniciamos uma análise do currículo mínimo desenvolvido pela Secretaria de Educação para uniformizar e ser aplicado em toda a rede. O objetivo deste artigo é analisar a construção do currículo mínimo, seus objetivos, o contexto em que foi elaborado e como os professores estão sendo formados (ou não) para trabalhar com esse documento. Devido a nossa atuação no ensino da História optamos por uma análise do currículo mínimo dessa disciplina escolar.

\section{Currículo Mínimo: contexto em que foi escrito e objetivos}

Em julho de 2010 o Ministério da Educação (MEC) divulgou os dados do Índice de Desenvolvimento da Educação Básica (IDEB) ${ }^{3}$. Os dados mediam o aprendizado e a taxa de aprovação de milhares de estudantes de todo país, matriculados nos níveis fundamental e médio no ano de 2009. Em uma escala de zero a dez, o país atingiu 4,6 pontos para os anos iniciais do ensino fundamental e 4,0 para os anos finais; e, 3,6 para o ensino médio. O estado do Rio de Janeiro conseguiu cumprir as metas impostas pela avaliação no que se refere ao ensino fundamental ${ }^{4}$. Entretanto, ficou abaixo média nacional. De acordo com as projeções do Instituto Nacional de Estudos e Pesquisas Educacionais Anísio Teixeira (Inep), o Rio deveria ter atingido a nota 3,4, em 2009, no ensino médio,

\footnotetext{
3 "Em 2007, foi criado o Índice de Desenvolvimento da Educação Básica (IDEB). O indicador, que mede a qualidade da educação, foi pensado para facilitar o entendimento de todos e estabelecido numa escala que vai de zero a dez. A partir deste instrumento, o Ministério da Educação traçou metas de desempenho bianuais para cada escola e cada rede até 2022. O novo indicador utilizou na primeira medição dados que foram levantados em 2005". Ele é calculado tendo como base a taxa de rendimento escolar (aprovação e evasão) e o desempenho dos alunos no Sistema Nacional de Avaliação da Educação Básica (SAEB) e na Prova Brasil. A classificação é feita numa escala de zero a dez. Informações retiradas do sítio do Ministério da Educação. Disponível em: http://portal.mec.gov.br/index.php?option=com_content\&view=article\&id=273\&Itemid=345. Acesso em: 09 ago. 2013.

${ }^{4} \mathrm{Na}$ avaliação entre as $5^{\mathrm{a}}$ e $8^{\mathrm{a}}$ séries (atuais $60,7^{\circ}, 8^{\circ}$ e $9^{\circ}$ anos), o Estado ficou em $21^{\circ}$ lugar no ranking entre os 26 estados do país. No que se referem as então denominadas $1^{a}$ à $4^{a}$ série o Rio de Janeiro ficou com $18^{\circ}$ lugar. Disponível em: <http://g1.globo.com/rio-dejaneiro/noticia/2010/07/ensino-medio-do-rio-tem-o-segundo-pior-desempenho-do-pais-noideb.html>. Acesso em: 08 ago. 2013.
} 
mas ficou com 3,3. Nesse nível de ensino, as escolas fluminenses tiveram o segundo pior resultado do país, atrás apenas do Piauí ${ }^{5}$.

A maioria dos estados ficou abaixo das metas estabelecidas pelo IDEB. No caso fluminense, a divulgação dos resultados gerou uma crise no comando da Secretaria de Educação. Tereza Porto, então secretária, estava no cargo há pouco mais de dois anos, tendo assumido, em fevereiro de 2008, com o objetivo de acabar com o déficit de professores e informatizar as escolas. A culpa do "problema" recaiu sobre a "herança deixada pelos governos anteriores", a antiga política de aprovação automática e a carência de professores - que segundo dados da época ultrapassavam os 10 mil. Em entrevista ao jornal O Globo, Porto argumentou que: "Nossos alunos de ensino médio vêm de um passado de má formação. Arrumamos a casa e temos feito melhorias. Mas as consequências só vão aparecer com o tempo. Este ano, sabíamos que ficaríamos estacionados" 6 .

Apesar do baixo rendimento do estado, Tereza Porto aparentava, nas diferentes entrevistas concedidas, certa esperança na melhoria dos resultados a partir das edições posteriores do IDEB. Poucos meses depois da divulgação das notas no IDEB Porto foi exonerada. O economista Wilson Risolia foi nomeado, em outubro de 2010, com a missão de melhorar o desempenho das escolas públicas do estado do Rio de Janeiro no IDEB. Na apresentação do novo dirigente da SEEDUC/RJ, o governador Sérgio Cabral lançou uma meta ambiciosa: estar entre os 5 melhores estados classificados em 2014. Em janeiro de 2011, o secretário anunciou os pilares da política educacional que seria adotada pelo estado a partir de sua gestão. As manchetes do jornal $\mathrm{O}$ Globo apresentavam, sob o título Choque de Ordem, as metas para os quatro anos seguintes. O plano, considerado extremamente economicista, estabeleceu cinco áreas de trabalho. Segundo Gaudêncio Frigotto et alii. (2011),

As cinco frentes de trabalho apresentadas teriam como objetivo atacar as questões pedagógicas, o remanejamento de gastos, a rede física, o diagnóstico de problemas e os cuidados com os

\footnotetext{
${ }^{5}$ Os dados foram obtidos a partir de pesquisas em periódicos publicados em 2010, no dia 05 de julho, quando foram divulgados os resultados do IDEB 2009. Disponível em: <http://ultimosegundo.ig.com.br/educacao/maioria-dos-estados-esta-abaixo-da-media-nacionalno-ideb/n1237697645633.html>. Acesso em: 08 ago. 2013.

6 Disponível em: <http://oglobo.globo.com/educacao/ideb-estado-do-rio-o-penultimo-do-ranking2983727>. Acesso em: 08 ago. 2013.
} 
alunos. As medidas mais destacadas, porém, foram a implantação de um regime meritocrático para a seleção de gestores; a realização de avaliações periódicas; o estabelecimento de metas de desempenho para balizar a concessão diferenciada de gratificações aos docentes; e a revisão das licenças dos 8 mil professores em tratamento de saúde.

Tais medidas reforçam a ideia de que os profissionais da educação são os únicos responsáveis pelos problemas educacionais e pelo baixo rendimento do estado nas avaliações nacionais. "Trata-se, portanto, de uma proposta que não vai ao fundamental e pega o pior atalho: premiar quem chega às metas, metas imediatistas, de lógica produtivista, que não incorporam medidas efetivas voltadas para uma educação pública de qualidade" (FRIGOTTO et. al., 2011). A política, nesse sentido, é imediatista. Não há uma preocupação com um planejamento pedagógico em longo prazo e com a busca de soluções para dois problemas cruciais: o alto índice de reprovação e a evasão escolar. Na contramão do projeto de meritocracia defendido por Risolia, não foram pensadas soluções para a efetiva melhoria das condições de trabalho do magistério estadual. Os salários só foram aumentados depois de uma greve de dois meses, em 2011. No ano seguinte, a rede estadual não teve reajuste salarial. Em 2013, o aumento foi de 80 reais no salário base do professor, o que, juntamente com as questões de cunho pedagógico, desencadeou nova greve na rede - iniciada a partir de agosto. Do mesmo modo, questões como o $1 / 3$ de planejamento e a diminuição dos alunos por classe não são respeitadas.

Meritocracia se tornou a palavra chave da gestão Wilson Risolia. O secretário tem pensado e aplicado essa política a partir de duas ideias principais. O primeiro refere-se à remuneração dos profissionais da educação a partir da pontuação obtida por seus alunos nas avaliações impostas pelo estado. Para Amanda Moreira da Silva (2012, p. 2), "a individualização dos aumentos salariais mediante remuneração por bônus, não somente encoraja a competição entre os professores, como também enfraquece as ações coletivas, atomizando os professores". Tal constatação surge a partir dos critérios da bonificação e, consequente, competição entre escolas e professores. Faz jus a bonificação: diretor geral, diretor adjunto, coordenador pedagógico, professores regentes (atuante em sala de aula) e demais servidores efetivos lotados nas unidades 
escolares contempladas. Foram estabelecidos os seguintes critérios: cumprir $100 \%$ do currículo mínimo, participar de todas as avaliações internas ou externas ( $85 \%$ dos alunos do turno diurno e $80 \%$ dos discentes do noturno devem realizar as provas, sem rasuras), professores e funcionários com presença mínima de $70 \%$ do ano letivo, atingir as metas estabelecidas pelo Índice de Desenvolvimento Escolar do Rio de Janeiro (IDERJ).

Essa avaliação tem gerado situações críticas, como as amplamente divulgadas pela imprensa. Num dos casos uma diretora subornou seus alunos para que fizessem a prova do Sistema de Avaliação da Educação do Estado do Rio de Janeiro (SAERJ) ${ }^{7}$ e outra que violou os lacres da prova. Ambas acabaram exoneradas, mas refletem o desespero dos professores. Em 2012 a Secretaria anunciou o Programa de Certificação.

Segundo: Trata-se mais uma vez de individualizar o salário docente, sem propor um aumento real. Por esse sistema os professores farão provas objetivando a análise do seu pleno conhecimento da disciplina, noções de planejamento escolar e de avaliações dos alunos. Os dois mecanismos, ao fim, lançam a culpa dos problemas educacionais inteiramente nas mãos dos professores. Se o aluno não vai bem nas provas externas, a culpa é do professor que deixou de cumprir o currículo mínimo. O professor não teve seu salário aumentado porque não foi bem no Programa de Certificação, e, portanto, não é qualificado.

Objetivando aferir as metas estabelecidas pela Secretaria foi o criado o currículo mínimo para a rede estadual e o Índice da Educação Básica do Rio de Janeiro (IDERJ), que "fornece um diagnóstico da escola em uma escala de zero a dez, baseando-se no Indicador de Desempenho (ID), medido através das notas do Sistema de Avaliação da Educação do Estado do Rio de Janeiro (SAERJ), e no Fluxo Escolar (IF)". O SAERJ foi criado em 2008, mas a partir de 2011 suas provas, elaboradas por um grupo da Faculdade de Educação da Universidade Federal de Juiz de Fora, passaram a incluir novos conteúdos para além da

\footnotetext{
7 "O Sistema de Avaliação da Educação do Estado do Rio de Janeiro (SAERJ) existe desde 2008 e foi criado com o objetivo de promover uma análise do desempenho dos alunos da rede pública do Rio de Janeiro nas áreas de Língua Portuguesa e Matemática do $4^{\circ}$ ano do Ensino Fundamental a 3a série do Ensino Médio". Informações disponíveis em: <http://www.rj.gov.br/web/seeduc/exibeconteudo?article-id=843535>. Acesso em: 09 ago. 2013. A partir de 2011, ocorreram mudanças significativas na aplicação da prova. Fazem as provas os alunos do $5^{\circ}$ e $9^{\circ}$ anos, do ensino fundamental, e alunos de todo o ensino médio.
} 
avaliação em Matemática e Língua Portuguesa e mais alunos passaram a fazer a prova. Todos os alunos de $5^{\circ}$ e $9^{\circ}$ anos do ensino fundamental e das séries do ensino médio participam bimestralmente da prova. Inicialmente, as provas eram de Matemática, Língua Portuguesa (ensino fundamental e médio), Ciências (ensino fundamental) e Química, Física e Biologia (ensino médio). No 10 bimestre de 2013 foram incluídos os conteúdos de História e Geografia.

A primeira avaliação da Secretaria de Educação em 2011, o Saerjinho, ocorreu no $1^{0}$ bimestre letivo em 13 de abril. De lá para cá as provas são bimestrais, as realizadas nos 10,20 e $3^{\circ}$ são diagnósticas, isto é, para a Secretaria, deve ser usada como uma "ferramenta pedagógica" e o professor analisa se as competências e habilidades estabelecidas para o bimestre foram atingidas. A prova SAERJ aplicada no $4^{\circ}$ bimestre é utilizada pelo IDERJ e para a distribuição da bonificação. As provas são simples, com questões objetivas, imagens e fragmentos de textos para contextualizar o aluno. É necessário um estudo que análise a elaboração, aplicação e os resultados dessa prova. Os conteúdos avaliados se referem ao currículo mínimo. Espera-se que o professor desenvolva todas as habilidades e competências expostas no currículo e o que aluno esteja habilitado a discutir e compreender todos os tópicos abordados no bimestre.

Os pesquisadores do campo do currículo advertem quanto à necessidade de distinção entre o currículo escrito e o currículo ativo ou real, isto é, tal como é vivenciado e posto em prática por professores e alunos nas salas de aula (GOODSON, 2008, p. 22). De acordo com Josefina Mello (2002), o currículo escrito é planejado e expressa diferentes intenções e interesses envolvidos em sua elaboração, podendo ou não se efetivar enquanto currículo em ação. É um artefato social que se articula a um contexto histórico. Nas palavras de Ivor Goodson (2008, p. 21), "[...] o currículo escrito nos proporciona um testemunho, uma fonte documental, um mapa do terreno sujeito a modificações; constitui também um dos melhores roteiros oficiais para a estrutura institucionalizada da escolarização". A fabricação do currículo é um processo social, "resultado de um processo de lutas no qual as prioridades sociais e políticas de um contexto histórico particular estão em negociação" (SANTOS, 2011, p. 32). 
O currículo mínimo do estado do Rio de Janeiro foi elaborado num curto espaço de tempo. Quirino et. al. (2011, p. 02), destacam que no "fim do ano letivo de 2010, o que havia eram as Orientações Curriculares. Não existia um 'currículo oficial'". As autoras explicam que em janeiro de 2011 os professores foram informados, via site da Secretaria, que "estava ocorrendo o processo de elaboração do currículo mínimo e que os professores poderiam contribuir com suas sugestões". Ainda segundo as pesquisadoras, "o período para sugestões foi curto, de apenas alguns dias, e em fevereiro já estava pronto o currículo mínimo". No documento, ao fim, é nomeada a equipe responsável por sua formulação, composta por seis professores da rede estadual e duas professoras doutoras $^{8}$. A maior parte dos professores regentes ficou de fora do processo. Fato é que, em fevereiro de 2011, início do ano letivo, o currículo mínimo foi implantado oficialmente na rede estadual. O documento foi criado com a intenção de servir como referência a todas as escolas estaduais do Rio de Janeiro.

\begin{abstract}
Sua finalidade é orientar, de forma clara e objetiva, os itens que não podem faltar no processo de ensino-aprendizagem, em cada disciplina, ano de escolaridade e bimestre. Com isso, pode-se garantir uma essência básica comum a todos e que esteja alinhada com as atuais necessidades de ensino, identificadas não apenas nas legislações vigentes, Diretrizes e Parâmetros Curriculares Nacionais, mas também nas matrizes de referência dos principais exames nacionais e estaduais. Considera-se também as compreensões e tendências atuais das teorias científicas de cada área de conhecimento e da Educação e, principalmente, as condições e necessidades reais encontradas pelos professores no exercício diário de suas funções (RIO DE JANEIRO, 2011, p. 03).
\end{abstract}

Dentre as finalidades do currículo mínimo ficam patentes a apreensão com as avaliações nacionais e estaduais e a tentativa de uniformizar o ensino ministrado na rede. Na matriz de 2011, os formuladores argumentam que cabe à escola e ao professor complementar o currículo mínimo "com aquilo que lhe é

\footnotetext{
${ }^{8}$ Sobre a escrita do Currículo Mínimo, por seus formuladores: "A concepção, redação, revisão e consolidação deste documento foram conduzidas por equipes disciplinares de professores da rede estadual, coordenadas por professores doutores de diversas universidades do Rio de Janeiro, que se reuniram e se esforçaram em torno dessa tarefa, a fim de promover um documento que atendesse às diversas necessidades do ensino na rede. Ao longo do período de consolidação, dezenas de comentários e sugestões foram recebidas e consideradas por essas equipes" (RIO DE JANEIRO, 2011, p. 04).
} 
específico, peculiar ou the for apropriado". De acordo com o documento, o "Currículo Mínimo apresentado busca fornecer ao educando os meios para a progressão no trabalho, bem como em estudos posteriores e, fundamentalmente, visa assegurar-Ihe a formação comum indispensável ao exercício da cidadania" (RIO DE JANEIRO, 2011, p. 03). A capacitação para a cidadania e formação para o trabalho estão presentes em artigos da Lei de Diretrizes e Bases da Educação Nacional (LBDN/1996). De acordo com a Lei, a educação tem como finalidade principal o "pleno desenvolvimento do educando", o que passa pelo conhecimento dos aspectos necessários ao exercício da cidadania e a preparação básica para o trabalho.

A elaboração do currículo mínimo dividiu-se em diferentes fases. $\mathrm{Na}$ primeira, 2011, foram priorizados, os anos finais do ensino fundamental e o ensino médio regular, os componentes de Matemática, Língua Portuguesa/Literatura, História, Geografia, Filosofia e Sociologia. Na segunda, em 2012, foram reformulados os nomeados acima e elaborados os de Artes, Ciências/Biologia, Educação Física, Língua Estrangeira, Física e Química. Ainda neste ano, foram produzidos os currículos mínimos das disciplinas que compõem o Curso Normal - formação de professores para as séries iniciais do ensino fundamental e que ainda é oferecido em algumas escolas da rede. Em 2013, das novas disciplinas: Resolução de Problemas Matemáticos e Leitura e Produção Textual. A partir deste ano o Currículo Mínimo passou a abranger os anos finais do ensino fundamental e ensino médio regular, Educação de Jovens e Adultos e Curso Normal em nível médio.

Pouco depois do início letivo de 2013, a SEEDUC baixou uma Resolução que dispõe sobre a implantação e acompanhamento do currículo mínimo ministrado na rede pública estadual de ensino do Rio de Janeiro (Resolução no 4.866/14 de fev. 2013). Como grande parte da atual política educacional do estado a Resolução é ambígua em sua formulação. No Art. $1^{0}$ reforça que o currículo mínimo tem por objetivo oferecer orientação aos professores sobre os conteúdos a serem ministrados e habilidades a serem desenvolvidas. Ainda de acordo com o artigo "as competências, habilidades e os conteúdos relacionados no currículo mínimo são aqueles definidos como imprescindíveis à aprendizagem básica de cada ano/série", podendo ser complementadas segundo as 
necessidades específicas de cada escola. Entretanto, ao tornar, no Art. 20, obrigatório o cumprimento do currículo mínimo, em sua totalidade, durante o ano letivo, limita-se a autonomia do professor.

Ao professor é facultado fazer ajustes no currículo, a fim de "melhorar a progressão de ensino", e inserir novos conteúdos ou habilidades, desde que as obrigatórias, determinadas pela SEEDUC, tenham sido cumpridas. Na mesma Resolução, se estabeleceu um modelo de acompanhamento do cumprimento do currículo mínimo. Estabeleceu-se a figura dos Integrantes do Grupo de Trabalho da Unidade Escolar (IGT's), responsáveis por fiscalizar, a palavra é essa, os planos de cursos elaborados pelos docentes e "as informações sobre o cumprimento do currículo mínimo junto aos professores regentes da unidade escolar". Os professores são obrigados a declarar bimestralmente, no Sistema Conexão Educação, plataforma onde são lançadas as notas e faltas dos discentes, as habilidades e competências desenvolvidas em todas as suas turmas (Figura 2). O cumprimento total do currículo é um dos critérios para a "bonificação". A avaliação estudantil aplicada pela Secretaria, o SAERJINHO e o SAERJ, é uma prova uniforme e que não atende as peculiaridades das diferentes escolas que a compõem.

Professores e alunos não são máquinas ou computadores pré-programados para reproduzir automaticamente os mecanismos de ensino elaborados pelo estado (QUIRINO et. al., 2011, 04). Os conhecimentos não são transmitidos na escola em sua integralidade, mas são reproduzidos e reelaborados pelos professores, que são participantes ativos no processo de criação da disciplina escolar (CARDOSO, 2008, p. 157). Da mesma forma, há que se levar em conta os alunos e sua "bagagem" ${ }^{9}$ e saberes provenientes de outras formações. O objetivo principal desta política educacional é a geração de índices positivos.

O currículo mínimo proposto pelo estado (currículo escrito), ao propor a obrigatoriedade de sua aplicação integral, não leva em consideração o currículo em ação, ou seja, as mudanças processadas na realidade de cada sala de aula por professores e alunos a partir das condições que lhes são possíveis de ensinar

\footnotetext{
9 Utilizamos a noção de "bagagem" apresentada por Helenice Rocha (2013). Em pesquisa realizada com professores fluminenses o uso da expressão se refere "ao que os alunos levam para as aulas de História". Para a autora, "o termo busca sintetizar determinadas condições que eles [os professores], não apenas os de História, atribuem aos seus alunos para aprender os conteúdos que devem ensinar em suas aulas" (p. 152).
} 
e aprender. Para Antonio Flávio Moreira (1998), "o ensino só se efetiva a partir de um currículo e este só se materializa no momento do ensino". Entretanto, como defende a professora Ana Maria Monteiro (2010, p. 482), não há como considerar o currículo sem se levar em conta o projeto educativo que se realiza na escola e nas aulas - "dinâmica de ensino na prática pedagógica". Neste contexto, o currículo mínimo apresentado pela SEEDUC/RJ configura-se, unicamente, como um mecanismo de controle. Às escolas e professores cabem, exclusivamente, a tarefa de implementação.

Figura 2: Tabela de cumprimento do Currículo Mínimo

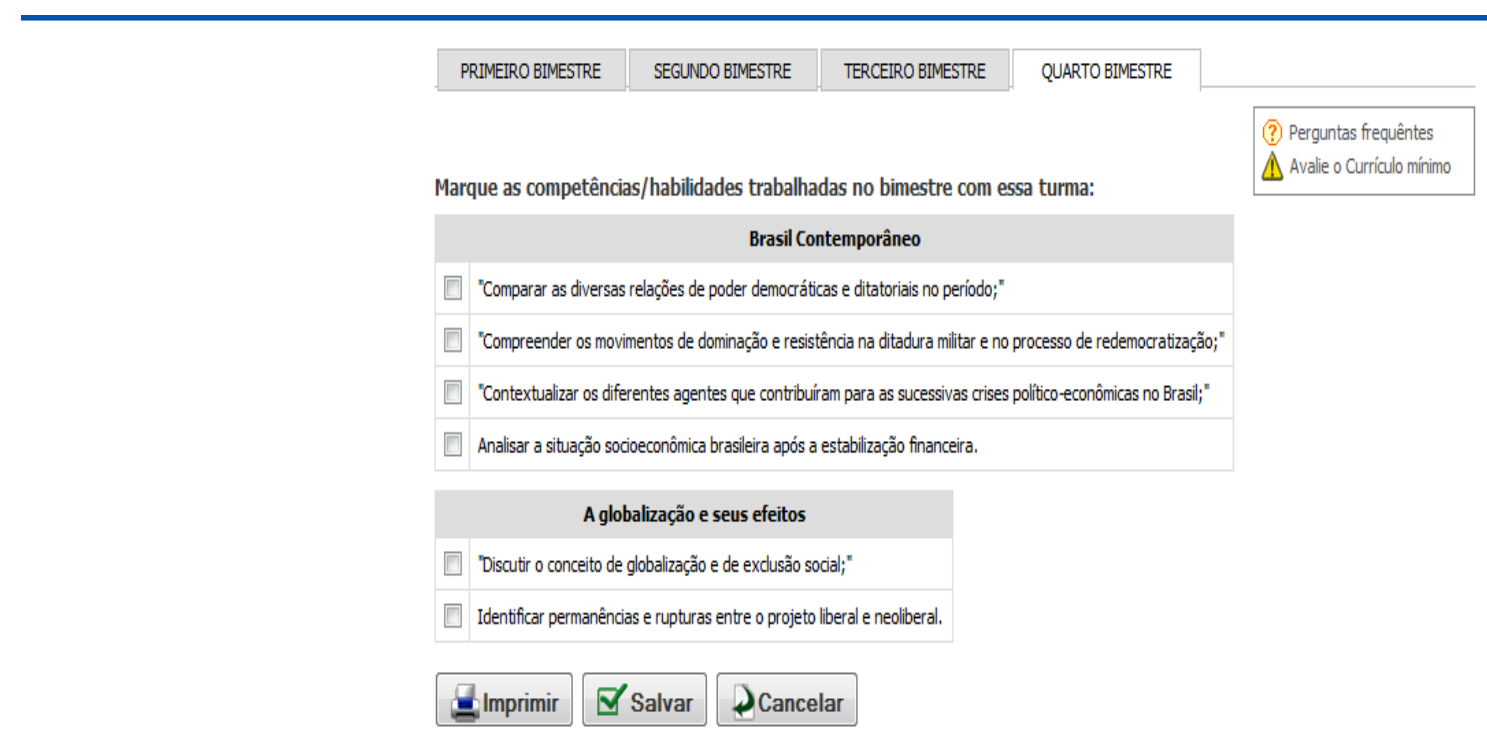

\section{O lugar da História no currículo da rede estadual e o currículo mínimo de História}

A historiadora Katia Abud (2011, p. 67), destaca que "desde o surgimento de um campo de conhecimento identificado como História, na Antiguidade Clássica, ela vem ocupando um lugar definido na formação dos jovens". No Brasil, o estudo da História nas escolas, constituiu-se no século XIX, a partir da fundação do Colégio Pedro II e "tem permanecido nos currículos escolares dos diferentes níveis do ensino básico e também como matéria dos cursos 
preparatórios ou de exames vestibulares brasileiros" (BITTENCOURT, 2009, p. 33). Desde o século XIX, diferentes objetivos foram atribuídos ao conhecimento histórico relacionados, dentre outros temas, a oratória e a formação humanística, a cidadania e a formação crítica ${ }^{10}$. Nos Parâmetros Curriculares Nacionais (BRASIL, 1998), do ensino fundamental, por exemplo, são apresentados os objetivos gerais do ensino da História. De acordo com o documento:

Espera-se que ao longo do ensino fundamental os alunos gradativamente possam ampliar a compreensão de sua realidade, especialmente confrontando-a e relacionando-a com outras realidades históricas, e, assim, possam fazer suas escolhas e estabelecer critérios para orientar suas ações (BRASIL, 1998, p. 43).

Ao longo das décadas o ensino da História sofreu mudanças nos métodos, conteúdos e finalidades, mas sua importância enquanto um saber necessário a formação dos jovens permanece. Apesar disso, suas aulas têm sofrido uma crescente diminuição de carga horária nos currículos escolares. Priorizam-se outros conteúdos e disciplinas. Com a lógica de indicadores como IDEB, IDERJ, SAERJ, em que se avalia Matemática e Língua Portuguesa, ocorre à hierarquização de disciplinas no currículo, ou seja, valorizam-se certos conhecimentos em detrimento de outros. Nas tabelas 1 e 2 podemos observar como isso tem acontecido na rede estadual do Rio de Janeiro ${ }^{11}$.

Tabela1: Distribuição de disciplinas no ensino fundamental ( $6^{\circ}$ a $9^{\circ}$ anos) ${ }^{12}$

\footnotetext{
10 Os historiadores salientam a influência da matriz francesa na constituição da História e como campo de conhecimento no Brasil. Para Abud (2011, p. 70), "a História escolar não nasceu no Brasil, aqui ela foi caudatária da europeia tal como foi na versão acadêmica". Entretanto, ao longo das décadas muitas outras correntes influenciaram esse ensino. Podemos destacar a perspectiva americana de aproximar o ensino da realidade do aluno e defesa dos Estudos Sociais, a partir da década de 1920. Uma análise da trajetória do ensino de História no Brasil fugiria ao escopo deste artigo. Há uma produção extensa sobre essa temática. Cf. Abud (2011), Brasil (1998, p. 19-29), Fonseca (2010), Nadai (1992/1993).

11 As tabelas foram construídas levando-se em conta a realidade do ensino diurno. Não trabalhamos, nesse artigo, a experiência da Educação de Jovens e Adultos (EJA) e Nova política de Educação de Jovens e Adultos (NEJA), que impõem outros elementos a análise. A NEJA foi pensada para alunos maiores de 18 anos ou aqueles que queiram concluir o Ensino Médio em menos tempo. O curso tem duração de dois anos, divididos em quatro módulos, um por semestre. Dois módulos terão disciplinas com ênfase em Humanas e os outros dois em disciplinas das Ciências da Natureza. Cada módulo tem um número reduzido de disciplinas: mínimo de cinco e máximo de sete. Em todos os módulos, o aluno terá Língua Portuguesa e Matemática. Nessa realidade, os conteúdos de Ciências Humanas são ainda mais reduzidos.

12 As Tabelas 1 e 2 foram confeccionadas a partir de análise do Quadro de Horários da rede estadual do Rio de Janeiro, referência ano de 2013.
} 


\begin{tabular}{ll}
\hline Disciplina escolar & Hora/aula (50 minutos) \\
\hline Língua Portuguesa e Literatura & 4 aulas \\
Leitura e Produção Textual & 2 aulas \\
Língua Estrangeira Obrigatória (Inglês) & 2 aulas \\
Matemática & 4 aulas \\
Resolução de Problemas Matemáticos & 2 aulas \\
(RPM) & \\
Ciências Físicas e Biológicas & 4 aulas \\
História & 3 aulas \\
Geografia & 3 aulas \\
Arte & 2 aulas \\
Educação Física & 2 aulas \\
& Total: 28 tempos \\
\hline
\end{tabular}

Na Tabela 1 apresentamos as disciplinas que compõem o currículo dos anos finais do ensino fundamental e os tempos de aula que possuem. Na década de 1990, História e Geografia tinham uma carga horária de 4 horas/aula cada. Nos primeiros anos de 2000, as duas disciplinas sofreram uma redução de sua carga horária pela metade. A partir do final da década consolidaram-se às 3 horas-aula. Em fevereiro de 2013, no início do ano letivo, foram incluídas duas novas disciplinas no currículo escolar. Resolução de Problemas Matemáticos (RPM) e Produção Textual foram estabelecidas pela Resolução $n^{\circ}$ 4843, de 03 de dezembro de 2012, publicada em Diário Oficial no dia 06 de dezembro de 2012. No que se refere a RPM deve ser estudada no 60, 70, $8^{\circ}$ e 90 anos do ensino fundamental e no $2^{\circ}$ ano do ensino médio. Produção Textual compõe a grade das séries finais do fundamental e do $3^{\circ}$ ano do ensino médio.

A inclusão dessas duas disciplinas reflete a preocupação da Secretaria com as avaliações externas. Ao defender a criação da disciplina Produção Textual, os seus formuladores destacam ser esta uma demanda evidenciada pelo Exame Nacional do Ensino Médio (ENEM) e pelo SAERJ. Os objetivos principais da nova matéria se relacionam a carência dos alunos em relação à compreensão da estrutura dos gêneros textuais e, conseqüente, dificuldade na produção do textual.

No concerne a RPM a justificativa para sua criação é semelhante. De acordo com o currículo mínimo da disciplina: "estudos e análises dos resultados das avaliações de larga escala comprovaram o baixo desempenho em Matemática, nos descritores relacionados à resolução de problemas". 
Prosseguindo, salienta que "para atender a esta demanda do processo de ensinoaprendizagem da Matemática, a Secretaria de Estado de Educação criou a disciplina: Resolução de Problemas Matemáticos" (RIO DE JANEIRO, 2013a, p. 02). São disciplinas obrigatórias, mas de caráter complementar ao trabalho desenvolvido pelos professores de Matemática e Língua Portuguesa. Criaram-se duas novas disciplinas, mesmo com a ausência de professores para essas áreas de atuação.

Tabela 2: Distribuição de disciplinas no ensino médio

\begin{tabular}{llll}
\hline Disciplina escolas/Ano & $\mathbf{1 0}^{\mathbf{0}}$ & $\mathbf{2 0}^{\mathbf{0}}$ & $\mathbf{3 0}^{\mathbf{0}}$ \\
\hline Língua Portuguesa e Literatura & 06 & 04 & 04 \\
Leitura e Produção Textual & $\overline{02}$ & $\overline{02}$ & 02 \\
Língua Estrangeira & 06 & 04 & 04 \\
Matemática & $\overline{02}$ & 02 & $\overline{02}$ \\
Resolução de Problemas Matemáticos & 02 & 02 \\
Física & 02 & 02 & 02 \\
Química & 02 & 02 & 02 \\
Biologia & 02 & 02 & 02 \\
História & 02 & 02 & 02 \\
Geografia & 01 & 01 & 02 \\
Filosofia & 01 & 01 & 02 \\
Sociologia & $\overline{02}$ & 02 & $\overline{02}$ \\
Arte & $\mathbf{0 2}$ & $\mathbf{2 8}$ \\
\hline Educação Física & 28 & 26 & 2 \\
\hline Total & & & \\
\hline
\end{tabular}

Da mesma forma que no nível fundamental, o médio privilegia o ensino de Matemática e Língua Portuguesa. Não há uma distinção entre Língua Portuguesa e Literatura. É o mesmo docente a ministrá-las. Uma das principais lutas do SEPE e dos professores da rede estadual de ensino é pela defesa de que nenhuma disciplina do currículo escolar tenha menos de 2 tempos de aula por semana. Cada tempo equivale há 50 minutos. Como ensinar Filosofia e Sociologia, no $1^{0}$ e $2^{0}$ anos do ensino médio, em apenas 50 minutos? ${ }^{13} \mathrm{O}$ currículo mínimo de Filosofia, por exemplo, destaca que não "se trata de formar o especialista em Filosofia neste nível de ensino, e sim, ir aos poucos

\footnotetext{
${ }^{13}$ Filosofia e Sociologia tornaram-se disciplinas obrigatórias em todas as séries do ensino médio a partir da Lei 11.684, de 02 de junho de 2008. A Lei altera o Art. 36 da Lei de Diretrizes e Bases da Educação Nacional (1996). Entretanto, mesmo antes da publicação da referida lei, uma Resolução, editada pela Câmara de Educação Básica do Conselho Nacional de Educação (CNE), de 21 de agosto de 2006, já orientava que se ofertassem as disciplinas no ensino médio.
} 
aproximando os estudantes, em sala de aula, do contato com o estilo reflexivo da filosofia, que é indispensável para se apreender a forma de abordagem filosófica" (RIO DE JANEIRO, 2012b). Para tanto, cada série do ensino médio é responsável pela inserção do aluno em uma etapa da abordagem filosófica e delimitação de um tema específico. $1^{0}$ ano: Iniciação ao processo de filosofar; 20 ano: Ser e conhecer; e, $3^{\circ}$ ano: 0 mundo do ser humano. O perfil da disciplina é claramente formador e de construção do pensamento. É uma disciplina de caráter formador.

Muito embora o ensino de Filosofia e Sociologia não sejam objeto deste artigo nos ajuda a situar uma questão básica: o currículo mínimo proposto pela SEEDUC não corresponde à realidade fluminense. Como ensinar conteúdos tão complexos em apenas 50 minutos de aula semanais? Já no que se refere a História, são 2 tempos de aula semanalmente, 1 a menos do que no ensino fundamental. Entretanto, em ambos os níveis de ensino, o currículo mínimo apresenta um extenso programa de competências e habilidades a serem desenvolvidas nos diferentes níveis de ensino. O pesquisador Marcelo Magalhães (2006, p. 63), ao analisar as Diretrizes Curriculares Nacionais e os Parâmetros Curriculares Nacionais para o ensino médio, salienta que essa forma de organização dos currículos, a partir de habilidades e competências, "tornou-se hegemônica na produção do governo brasileiro desde o final dos anos de 1990". Assim, é comum que tais documentos não listem os conteúdos a serem ministrados, mas os objetivos ou "os procedimentos que permitam ao aluno aprender a conhecer".

O currículo mínimo de História é precedido por uma breve apresentação de aspectos que compõem o ensino desta disciplina escolar. Destaca que o objetivo principal é "oferecer ao conjunto das escolas da rede uma base curricular comum" (RIO DE JANEIRO, 2012a, p. 03). Desta forma, na concepção defendida pelo secretário Risolia, não existiria uma discrepância de conteúdos entre as escolas estaduais, já que existem habilidades e competências pré-estabelecidas para cada bimestre letivo. Entretanto, os formuladores do currículo mínimo de História defendem um modelo curricular aberto, ou seja, não impõem uma abordagem ou método. Os conteúdos são amplos e genéricos, as competências e habilidades é que não são. A apresentação dos conteúdos, habilidades e 
competências seguem a mesma lógica no ensino fundamental e médio, exemplificando:

90 ano/Ensino Fundamental

Conteúdo - A Segunda Guerra Mundial e a Bipolarização

Habilidades e Competências:

- Identificar o contexto histórico da Segunda Guerra;

- Compreender o significado histórico das relações de poder entre as nações;

- Analisar o holocausto no contexto da Segunda Guerra Mundial;

- Discutir os conceitos de hegemonia, dominação e Guerra Fria. (RIO DE JANEIRO, 2012, p. 11).

Os verbos principais são perceber, reconhecer, identificar, entender, compreender, analisar, discutir, promover, contextualizar, correlacionar, caracterizar, relacionar, comparar, estimular e questionar. Os conteúdos, como exposto o da Segunda Guerra Mundial, se ligam a habilidades e competências gradativas, isto é, do mais simples (identificar) ao mais complexo (analisar e discutir). A preparação das aulas deve levar em conta muito mais as habilidades e competências do que propriamente o conteúdo. A proposta do currículo mínimo, tal como defendida pela SEEDUC, tem a pretensão de uniformizar o ensino da rede, porém sua aplicação depende do professor e as escolhas que este irá realizar ao preparar suas aulas, as relações de ensino-aprendizagem, as condições de sua escola e tantos outros aspectos que condicionam o ensino. Há um currículo escrito (papel) e outro em ação. Portanto, a uniformização é em termos e restrita ao plano das ideias. Quanto às perspectivas teóricopedagógicas o currículo

[...] procurou enfatizar os conceitos, vendo-os como peças chaves para a construção de uma perspectiva crítico-construtivista de conhecimento. Esse enfoque também almeja produzir efeitos na vida dos alunos ao dar importância às identidades dos sujeitos envolvidos no cotidiano escolar como cidadãos, como agentes de inclusão e promoção social (RIO DE JANEIRO, 2012a, p. 03).

Os pesquisadores Margarida de Oliveira e Itamar Freitas (2012, p. 272), em artigo recente onde analisam o perfil de 18 propostas curriculares estaduais produzidas entre 2007 e 2012, argumentam que no que concerne as funções ou objetivos do ensino da disciplina escolar História a maior parte das propostas 
apresentam 4 finalidades: "a formação de identidades, a capacitação para a cidadania, a leitura crítica da realidade e a compreensão dos procedimentos meta-históricos". As três primeiras perspectivas apresentadas pelos historiadores, como é possível observar no fragmento citado, ficam patentes no currículo mínimo do Rio de Janeiro. Uma das principais preocupações dos seus formuladores está na formação crítica e cidadã do aluno da rede estadual ou o que Oliveira e Freitas (2012) definem como "a leitura da realidade" ou a "responsabilidade de desenvolver no/com o aluno as habilidades de observar, interpretar, compreender e pensar". Da mesma forma, há a preocupação com a construção de valores: "promover o desenvolvimento de atitudes de respeito e tolerância à diversidade religiosa" (70 ano); "estimular o respeito à diversidade cultural" (90 ano); "desenvolver comportamentos de tolerância religiosa" (10 ano/Ensino Médio).

O documento concebe a escola como espaço de produção de conhecimento histórico. Desta forma, "reconhece-se que o conhecimento científico tem seus objetivos sociais e é reelaborado, de diversas maneiras, para o conjunto da sociedade" (BRASIL, 1998). Professores e alunos exercem um papel ativo no processo de construção da disciplina História escolar.

A escola é parte integrante do todo social, portanto, os conteúdos históricos a serem ministrados não podem estar dissociados da realidade em que se insere a escola e o aluno. Entretanto, não há referências ao ensino da História Fluminense, principalmente do interior ${ }^{14}$, ou Local (ou das cidades que compõem do estado) e, mesmo, dos acontecimentos mais próximos ao contexto histórico atual. O documento, mesmo que de forma involuntária, reflete uma política educacional pouco planejada e apresenta algumas ambiguidades. Embora destaque que não exista uma escola, professor ou aluno modelos e que a realidade do estado é diversificada o que temos é um currículo mínimo que deve ser aplicado integralmente. Há, por conseguinte, um descompasso entre o que pensaram os formuladores do currículo mínimo de História e o que vem sendo

\footnotetext{
14 Durante muitos anos a cidade do Rio de Janeiro foi Capital do Brasil e, portanto, palco de importantes acontecimentos da história nacional. Nesse sentido, questões como a expansão cafeeira, processada no século XIX, ou as Reformas Pereira Passos, do início do século XX, mesmo que ocorridas no Rio de Janeiro, refletem aspectos gerais da História do Brasil e não necessariamente das especificidades fluminenses.
} 
defendido pela SEEDUC, enquanto política de ensino. Para a comissão que elaborou o currículo um dos principais desafios do professor é,

[...] impedir que o que se ensina nas aulas de História fique associado a um lugar de memorização, de um conjunto de fatos e de datas desconectados da realidade e que só possuem alguma serventia para fazer exercícios ou as provas que logo são ignorados (RIO DE JANEIRO, 2012, p. 04).

A assertiva é verdadeira e, certamente, é o que mais preocupa o professor de História durante o processo de produção de sua aula ${ }^{15}$. Entretanto, a SEEDUC ao tornar obrigatória a aplicação de um extenso currículo, com poucas brechas para complementação - devido a curta carga horária de História - , e pressionar o docente a preparar os seus alunos para realização das provas externas bimestrais, SAERJINHO e SAERJ, rompe com a bela frase disposta no currículo escrito. Na ação temos o incentivo à memorização. Prioriza-se a quantidade (as notas nas avaliações externas) em detrimento da qualidade de ensino. Concordamos assim com a argumentação de Quirino et alii (2011, p. 02), quando salientam que "o currículo não é, portanto, um documento de transmissão desinteressada de conteúdos, é uma ferramenta de manipulação dos saberes, ou melhor, do que é interessante se saber". O professor se torna um mero reprodutor de um currículo, que mais do que um "instrumento de planejamento do professor", serve como uma camisa de força.

O que os alunos devem aprender com o ensino de História são apresentados, no currículo mínimo, a partir de conteúdos, habilidades e competências. Apesar de ser um consenso a impossibilidade de se estudar toda a História da humanidade, em diferentes tempos e sociedades, e a necessidade de seleção dos conteúdos a serem ensinados a maior parte das propostas curriculares apresentam um extenso conteúdo. O currículo mínimo fluminense não é diferente. A opção é pela divisão cronológica tradicional da História,

\footnotetext{
15 Por si essa é uma temática que tem merecido a atenção dos pesquisadores. Maria Stephanou (1998), por exemplo, salienta que "embora insistentemente apontada pelos autores e reconhecida, diante dessa crítica, tanto os professores quanto os estudantes acabam não tendo uma experiência ou não encontrando uma alternativa que escape a exposição oral, textos, questionários, decoreba, maniqueísmos [...]. O currículo mínimo de História tenta incorporar essa discussão, mas não apresenta caminhos ou possibilidades". Cabe ao professor, em sua sala de aula, buscar alternativas para um ensino de história problematizador.
} 
delimitada em grandes marcos: Pré-História, História Antiga, Medieval, Moderna e Contemporânea, integrando-se os cinco continentes. O ensino da História e cultura afrobrasileira e indígena, tornados obrigatórios a partir das Leis no 10.639/03 e 11.645/08, aparecem no currículo em diferentes anos. As inclusões são tradicionais. Exemplo: A História da África aparece em contextos como o de Expansão Marítima e Imperialismo. Não há tópicos específicos sobre a História da África Antiga (exceto Egito e Núbia), anterior ao processo de exploração e colonização. Cabe ao professor pensar nas melhores abordagens sobre as temáticas.

O pesquisador canadense Maurice Tardif (2008), ao analisar a construção dos saberes docentes, argumenta "que o corpo docente não é responsável pela definição nem pela seleção dos saberes que a escola e a universidade transmitem". Concordamos em partes com o autor. No momento atual, os saberes curriculares a serem ensinados na disciplina escolar História já se encontram consolidados ${ }^{16}$. Dentre cada um dos grandes períodos históricos se situam os conteúdos - Imperialismo, Era Vargas, Guerra Fria, citando alguns que os alunos precisam ter tido acesso durante sua formação na escola básica. Dentre este corpus de conteúdos se situa a seleção. Desta forma, não há um currículo mínimo no singular, mas currículos e diferentes formas de apreensão.

Para a educadora Cecília Borges (2004, p. 31), "cada professor desenvolve uma forma particular de trabalhar o conhecimento, decorrente da interpretação que faz do programa e também dos próprios conteúdos, assim como de sua visão de mundo, dos seus valores e princípios". De acordo com pesquisadores como Tardif (2008) e Borges (2004), os professores, diariamente, mobilizam um conjunto de sabres durante a sua prática docente. No exercício de sua função e na prática de sua profissão os professores, segundo Tardif (2008, p. 38), "desenvolvem saberes específicos, baseados em seu trabalho cotidiano e no conhecimento de seu meio". É o que o pesquisador denomina enquanto "cultura docente em ação". Pode-se dizer que na prática docente inicia-se outra

\footnotetext{
${ }^{16}$ Não cabe neste artigo uma discussão das disputas travadas ao longo dos séculos XIX e XX acerca dos conteúdos privilegiados pelo ensino da História. Conteúdos e temas já disputaram a primazia: História Profana e História Sagrada, História da Civilização e História do Brasil e, mesmo, História e Estudos Sociais (enquanto perspectiva de aproximar o ensino da realidade do aluno). Há uma vasta literatura sobre o tema. Algumas das obras citadas nas referências bibliográficas ajudam a explicar essas questões.
} 
formação: uma formação da prática e pela prática. São os saberes experienciais, que "têm origem na prática cotidiana dos professores em confronto com as condições da profissão" (p. 52). A prática docente promove o início de outra formação, para além daquela adquirida nos cursos de graduação em História. De certa forma, é uma formação continuada.

Na mesma Resolução em que definiu a obrigatoriedade da aplicação integral do currículo mínimo, a SEEDUC estabeleceu uma formação continuada. No Art. $6^{\circ}$ estabelece que a "Secretaria de Estado de Educação do Rio de Janeiro promoverá, gradualmente, a oferta de cursos de formação continuada aos professores, alinhados ao Currículo Mínimo" (RESOLUÇÃO SEEDUC no 4.866). Anualmente são abertas turmas de formação continuada. A proposta é de um curso a distância, com encontros presenciais bimestrais. No edital deste ano, a Fundação Centro de Ciências e Educação Superior a Distância do Estado do Rio de Janeiro (FUNDAÇÃO CECIERJ), responsável pelo curso e pela seleção argumenta que:

Com a implementação do Currículo Mínimo pela SEEDUC, surgiu à necessidade de intensificar a capacitação e formação do professor para o uso do currículo no cotidiano da sala de aula, através de diferentes ações, entre elas a elaboração de Planos de Trabalho, que busquem, cada vez mais, a autonomia autoral $[\ldots]$

Pretende-se que o processo se traduza, de fato, em uma mudança nos procedimentos de ensino e aprendizagem na sala de aula, ou seja, deseja-se que a formação continuada possa, ao mesmo tempo, contribuir para elevar o nível de conhecimento da área específica e da prática pedagógica. (FUNDAÇÃO CECIERJ, 2013, p. 01).

Uma pergunta surge ao professor que lê o edital e inicia o curso de formação de professores: uma formação continuada ou a propósito da aplicação do currículo? Anualmente são disponibilizadas vagas para Biologia, Ciências, Física, Geografia, História, Língua Portuguesa, Matemática, Química e Sociologia. No caso da História, são oferecidas turmas para professores regentes do 90 ano do ensino fundamental e $1^{0}, 2^{\circ}$ e $3^{\circ}$ anos do ensino médio. É um curso de aperfeiçoamento de 180 horas, cujas disciplinas têm como objetivo cobrir o 
currículo mínimo. Sua estrutura se liga a aplicação do currículo mínimo de História.

Tabela 3: Formação Continuada e suas disciplinas

\begin{tabular}{lc}
\hline \multicolumn{1}{c}{ Disciplinas } \\
\hline \multicolumn{1}{c}{ Núcleo Obrigatório } & $\begin{array}{c}\text { Carga } \\
\text { Horária }\end{array}$ \\
$\begin{array}{l}\text { Tópicos de Conteúdos do Currículo Mínimo do } 10 \text { Bimestre } \\
\text { Letivo }\end{array}$ & 40 horas \\
$\begin{array}{l}\text { Tópicos de Conteúdos do Currículo Mínimo do } 20 \text { Bimestre } \\
\text { Letivo }\end{array}$ & 40 horas \\
$\begin{array}{l}\text { Tópicos de Conteúdos do Currículo Mínimo do } 30 \text { Bimestre } \\
\text { Letivo }\end{array}$ & 40 horas \\
$\begin{array}{l}\text { Tópicos de Conteúdos do Currículo Mínimo do } 40 \text { Bimestre } \\
\text { Letivo } \\
\text { Currículo Mínimo: contexto e discussões }\end{array}$ & 40 horas \\
\hline
\end{tabular}

Fonte: Fundação Cecierj (2013, p. 02-03).

O curso se divide em blocos, de acordo com os bimestres letivos, totalizando 4, e cada bloco apresenta os tópicos do currículo mínimo. $\mathrm{Na}$ formação continuada para o professor de História do 90 ano, por exemplo, o primeiro módulo apresenta os conteúdos "Brasil - República Velha: federalismo, coronelismo, política dos governadores. Revoltas rurais e urbanas: Canudos e Vacina" e "A Primeira Guerra Mundial e seus desdobramentos". Cada conteúdo é apresentado sobre a forma de "Planejamento", textos-base sobre o tema em questão, e "Desenvolvimento", quando se espera que o professor cursista aplique um Roteiro de Ação, pré-estabelecido, em suas aulas. Nesta fase, o professor é livre para fazer adaptações ao Roteiro. As discussões se processam numa plataforma online e mediada por tutores. Ao final do bimestre letivo, o professor cursista deve apresentar o seu próprio Roteiro de Ação. Cumpre questionar como essa formação continuada contribui para os objetivos da Secretaria de "elevar o nível de conhecimento da área específica e da prática pedagógica".

O grande problema deste tipo de formação é que o que se expõe e, conseqüentemente, cobra do professor, não condiz com a realidade das salas de aula e das escolas fluminenses. Em uma aula não são ministrados apenas 
conteúdos. Existem relações que se processam entre professores e alunos. Há, de certo modo, uma gestão disciplinar. Essas relações não estão na formação continuada do estado. Ao docente cabe a responsabilidade de trabalhar os conteúdos do currículo mínimo tendo ou não condições estruturais para isso. Desta forma, ao mesmo tempo em que a SEEDUC defende que os professores utilizem mecanismos da formação continuada e a defesa da utilização de recursos digitais, que dependem de computador, wi-fi, datashow, não oferece as condições para tal. Ao professor resta, diariamente, estimular seus alunos, elaborar novas formas de ensino, lutar pela autonomia pedagógica, construir sua prática pedagógica. Para isso, seguindo Tardif (2008), não há uma definição acabada. Lidar com essas situações é formador!

\section{Considerações finais}

Diante da pequena quantidade de trabalhos e pesquisas sobre o currículo mínimo adotado nas escolas fluminenses a partir de fevereiro de 2011, propusemos um estudo exploratório sobre a educação estadual durante parte do Governo Sérgio Cabral e a partir da gestão do secretário Wilson Risolia. Conforme Maria Stephanou (1998), "explicitamos aqui uma determinada forma de olhar, situada no espaço [...] em que nos constituímos como sujeito professor-pesquisador". Portanto, este artigo não tem a pretensão de esgotar as temáticas abordadas, mas apresentá-las e instigar o interesse dos pesquisadores sobre o tema. É um objeto de pesquisa em aberto. Objetivamos apresentar o contexto em que este currículo foi elaborado e algumas de suas características.

A proposta de ensino presente no currículo mínimo de História não é ruim, mas, acompanhada de uma política de ensino autoritária, coercitiva e da ausência de investimentos na melhoria da qualidade da educação fluminense, torna-se difícil a sua concretização na realidade das salas de aula. A gestão Risolia propõe uma reforma para inglês ver. Ao adotar o sistema da meritocracia e a bonificação por metas há uma forte pressão pela aprovação discente, já que este é um dos pontos na avaliação de bom desempenho das escolas. Consideramos que a elaboração do currículo, de forma geral, se liga a uma 
pretensão da SEEDUC de unificar a avaliação na rede estadual. Desta forma, a cada bimestre o SAERJINHO fica responsável por verificar se o professor ministrou todo o currículo mínimo. A real preocupação, nesse sentido, está na melhoria dos índices nas avaliações externas e, não necessariamente, no aprendizado de nossos alunos.

Com a priorização dos conteúdos curriculares de Língua Portuguesa e Matemática, as disciplinas de Ciências Humanas (História, Filosofia e Sociologia) perdem, aos poucos, o seu lugar no currículo da rede estadual. Espera-se que o professor ministre um amplo conhecimento em curto espaço de tempo e nem sempre com melhores recursos. No momento em que o magistério carioca e fluminense se encontra, mais uma vez, em luta pela qualidade de ensino cabe encerrar essas notas com palavras que expressam a complexidade do ato de ensinar.

\footnotetext{
Ensinar envolve gosto, paixão, identificação pela docência, pelos conteúdos ensinados. Ensinar envolve encontrar um sentido no ato de ensinar, um sentido que diz respeito ao voltar-se para o outro, ao sentir-se bem na relação com o outro e ter gosto, prazer no trabalho que se está realizando e nos conteúdos, saberes, que estão sendo ensinados (BORGES, 2004, p. 213).
}

\section{Referências}

\section{Documentos:}

BRASIL. Secretaria de Educação Fundamental. Parâmetros Curriculares Nacionais: História. Brasília: MEC/SEF, 1998.

FUNDAÇÃO CECIERJ. EDITAL EXT-CECIERJ No 002/2013. Disponível em: $<$ http://projetoseeduc.cecierj.edu.br/principal/formacao-continuada.php $>$. Acesso em: 15 ago. 2013.

RESOLUÇÃO SEEDUC No 4.866 DE 14 DE FEVEREIRO DE 2013. Dispõe sobre a implantação e acompanhamento do currículo mínimo a ser instituído na rede de ensino pública do Estado do Rio de Janeiro. Disponível em: $<$ http://mminerva.blogspot.com.br/2013/02/resolucao-seeduc-n-4866-de-14de.html>. Acesso em: 01 nov. 2013. 
RIO DE JANEIRO. Currículo Mínimo - História. Rio de Janeiro: Secretaria de Estado de Educação do Rio de Janeiro, 2012a.

RIO DE JANEIRO. Currículo Mínimo - Filosofia. Rio de Janeiro: Secretaria de Estado de Educação do Rio de Janeiro, 2012b.

RIO DE JANEIRO. Currículo Mínimo - Resolução de Problemas Matemáticos. Rio de Janeiro: Secretaria de Estado de Educação do Rio de Janeiro, 2013a.

RIO DE JANEIRO. Currículo Mínimo - Produção Textual. Rio de Janeiro: Secretaria de Estado de Educação do Rio de Janeiro, 2013b.

\section{Internet:}

FRIGOTTO, G.; GAMA, Z.; ALGEBAILE, Eveline; MOTTA, Vânia da; Plano de Metas da Educação do Rio de Janeiro: do economicismo ao cinismo. Publicado em: 13 jan. 2011. Disponível em: $<$ http://www.uff.br/observatoriojovem/materia/plano-de-metas-daeduca\%C3\%A7\%C3\%A3o-do-rio-de-janeiro-do-economicismo-ao-cinismo > . Acesso em: 19 out. 2013.

IG. Último segundo. Maioria dos Estados está abaixo da média nacional no Ideb. Publicado em: 05/07/2010. Disponível em:

$<$ http://ultimosegundo.ig.com.br/educacao/maioria-dos-estados-esta-abaixo-damedia-nacional-no-ideb/n1237697645633.html>. Acesso em: 08 ago. 2013.

O GLOBO. Ensino Médio do Rio tem o segundo pior desempenho do país no Ideb. Publicado em: 05/07/2010. Disponível em: http://g1.globo.com/rio-dejaneiro/noticia/2010/07/ensino-medio-do-rio-tem-o-segundo-pior-desempenhodo-pais-no-ideb.html>. Acesso em: 08 ago. 2013.

O GLOBO. Ideb: Estado do Rio é o penúltimo do ranking. Publicado em: 05/07/2010. Disponível em: <http://oglobo.globo.com/educacao/ideb-estadodo-rio-o-penultimo-do-ranking-2983727>. Acesso em: 08 ago. 2013.

O GLOBO. Diretora de colégio estadual suborna alunos e é exonerada. Publicado em: 21/12/2012. Disponível em: <http://oglobo.globo.com/educacao/diretorade-colegio-estadual-suborna-alunos-e-exonerada-7118060>. Acesso em: 03 nov. 2013

MINISTÉRIO DA EDUCAÇÃO (MEC). Índice de Desenvolvimento da Educação Básica (IDEB). Disponível em:

$<$ http://portal.mec.gov.br/index.php?option=com content\&view=article\&id $=273$ \&Itemid=345> . Acesso em: 09 ago. 2013.

SEEDUC. Sistema de Avaliação da Educação do Estado do Rio de Janeiro. Disponível em: <http://www.rj.gov.br/web/seeduc/exibeconteudo?article$\underline{\mathrm{id}=843535}$ >. Acesso em: 09 ago. 2013. 
SEPE. Dieese: perdas salariais do magistério estadual atingem até $23,70 \%$, mas projeto de Cabral concede apenas 7\%. Publicado: 14/05/2013. Disponível em: Disponível em: <http://www.seperj.org.br/ver noticia.php?cod noticia $=4041>$. Acesso: 08 ago. 2013.

SEPE. Abaixo-assinado Carta aberta de professores e professoras da Faculdade de Educação da UFRJ ao Secretário de Educação do Governo do Rio de Janeiro, Sr. Wilson Risolia. Pedido de exoneração. Publicado: 17/07/2013. Disponível em: <http://sepe-sg.blogspot.com.br/2013/07/abaixo-assinado-carta-abertade.html>. Acesso em: 08 ago. 2013.

\section{Artigos, capítulos e livros:}

ABUD, K. Currículos de História: a criação da tradição e o código disciplinar. In: FONSECA, Selva; GATTI JúNIOR, Décio (Orgs.). Perspectivas do Ensino de História: Ensino, cidadania e consciência histórica. Uberlândia: EDUFU, 2011.

BITTENCOURT, C. Ensino de História: fundamentos e métodos. São Paulo: Cortez, 2004.

BORGES, C. O professor da educação básica e seus saberes profissionais. Araraquara: JM Editora, 2004.

CARDOSO, O. Para uma definição de Didática da História. Revista Brasileira de História, São Paulo, v. 28, n. 55, p. 153-170, jan./jun. 2008.

FONSECA, S. G. Caminhos da História ensinada. $11^{\text {a }}$ ed. Campinas/SP: Papirus, 2010.

GOODSON, I. Currículo: Teoria e história. 10ª ed. Petrópolis/RJ: Vozes, 2008.

MELLO, J. História da disciplina Didática Geral em uma escola de formação de professores: (re) apropriação discursos acadêmicos nos anos de 1980 e 1990. 2002. 189f. Dissertação (Mestrado em Educação) - Faculdade de Educação, UFRJ, 2002.

MAGALHÃES, M. Apontamentos para pensar o ensino de História hoje: reformas curriculares, ensino médio e formação do professor. Tempo, v. 11, n. 21, p. 5974, jul./dez. 2006.

MONTEIRO, A. M. Didática da História e Teoria da História: produção de conhecimento na formação de professores. In: PEREIRA, J. S; SIMAN, Lana Mara de Castro (Orgs.). PARTE IV - Ensino de História: convergências e tensões no campo da formação e do trabalho docente. Belo Horizonte: Autêntica, 2010. p. 479-499. Disponível em: <www.fae.ufmg.br/endipe/livros/Livro 6.PDF>. Acesso em: 07 set. 2013.

MOREIRA, A. F. Didática e currículo: questionando fronteiras. Revista Educação \& Realidade, v. 23, n. 2, p. 11-26, ago./dez. 1998. 
NADAI, E. O ensino de História no Brasil: trajetória e perspectiva. Revista Brasileira de História, São Paulo, v. 13, n 25/26, p. 143-65, set. 1992/ago. 1993.

OLIVEIRA, M.; FREITAS, I. Currículos de história e perspectivas de aprendizagem para os anos finais do ensino fundamental no Brasil (2007-2012). História Hoje, v. 1, n. 1, p. 269-304, 2012.

ROCHA, H. Sem bagagem não se ensina e nem se aprende História. In: SILVA, Cristiani Bereta; ZAMBONI, E. (Org.). Ensino de História, memória e culturas. Curitiba: CRV, 2013.

SANTOS, B. B. M. dos. O currículo da disciplina escolar história no Colégio Pedro II - a década de 1970 - entre a tradição acadêmica e a tradição pedagógica: a história e os estudos sociais. Rio de Janeiro: Mauad X/FAPERJ, 2011 a.

SILVA, A. M. Precarização do trabalho docente e meritocracia na educação: o olhar empresarial dos governos e a resistência do professorado da rede pública do Estado do Rio de Janeiro. In: VII Simpósio Nacional Estado e Poder, 2012, Uberlândia. Simpósio Nacional Estado e Poder. Uberlândia. 2012. p. 1-10.

STEPHANOU, M. Instaurando maneiras de ser, conhecer e interpretar. Revista Brasileira de História, São Paulo, v. 18, n. 36, p. 15-38, 1998.

TARDIF, M. Saberes docentes e formação profissional. 9a Ed. Petrópolis/RJ: Vozes, 2008.

QUIRINO, M. J. da S. de O.; PEREIRA, C.; LEAL, C.; OLIVEIRA, V. L. de. Políticas Curriculares: Uma Breve Crítica ao Currículo Mínimo Implantado no Estado do Rio de Janeiro. VIII ENPEC Encontro Nacional de Pesquisa em Educação em Ciências: Campinas, 2011. 